\title{
A Tale of Two Hormones: Role of Leptin and Insulin in Hippocampal Synaptic Function
}

\author{
Jenni Harvey ${ }^{*}$
}

\author{
Neurosciences Institute, Division of Pathology and Neuroscience, Ninewells Hospital and Medical School, University of \\ Dundee, Dundee DD1 9SY, UK
}

\begin{abstract}
It is well documented that the endocrine hormones, leptin and insulin provide signals to specific hypothalamic brain regions to regulate energy balance. However, the past decade of research has not only revealed the widespread expression of insulin and leptin receptors in the CNS, but has also identified numerous additional functions of these hormones in the brain. In particular, there is growing evidence that these hormones markedly influence hippocampal excitatory synaptic transmission as well as hippocampal synaptic plasticity. More recent studies have also identified links between dysregulation of leptin and insulin systems and the development of neurodegenerative disorders such as Alzheimer's disease. Here we review the recent evidence supporting a role for these hormones in modulating hippocampal synaptic function in health and disease.
\end{abstract}

\section{INTRODUCTION}

The obese gene product, leptin is a $16 \mathrm{KDa}$ protein hormone that is produced primarily by white adipose tissue and it circulates in the plasma at levels relative to body adiposity $[1,2]$. In addition to acting on a number of peripheral tissues, several lines of evidence indicate that leptin can enter the CNS via transport across the blood brain barrier. The hypothalamus was one of the first regions of the brain that was identified as a leptin-sensitive target. Indeed, it is now well documented that leptin plays a key role in a number of hypothalamic functions including the regulation of energy homeostasis [3], bone formation [4], reproduction [5] and the hypothalamic-pituitary-adrenal axis [6]. However, recent studies have demonstrated that leptin is a pleitropic cytokine that evokes wide-spread biological actions on numerous extra-hypothalamic brain regions, including hippocampus.

Insulin is a small $6 \mathrm{KDa}$ protein that is made in large amounts by pancreatic beta cells. Following stimulation of beta cells, insulin is released into the circulation where it regulates the uptake of glucose. However, in a manner similar to leptin, insulin is also capable of crossing the blood brain barrier [7] and has been shown to influence numerous CNS functions, including hypothalamic driven feeding behaviour [8], excitatory and inhibitory synaptic transmission [9-11] as well as neuronal survival [12]. Impairments in the insulin signaling pathway and/or resistance to insulin are also thought to contribute to the development of neurodegenerative conditions such as Alzheimer's disease (AD) [13].

In this review we will highlight the putative role of leptin and insulin and their respective signaling cacades in synaptic function. In particular the influence of these hormones on hippocampal excitatory synaptic transmission and synaptic plasticity will be addressed. Moreover the role of these

*Address correspondence to this author at the Neurosciences Institute, Division of Pathology and Neuroscience, Ninewells Hospital and Medical School, University of Dundee, Dundee DD1 9SY, UK; Tel: +44 1382 496628; Fax: +44 1382 667120; E-mail: j.z.harvey@dundee.ac.uk hormonal systems in CNS driven diseases will also be explored as several lines of evidence have implicated dysfunctional insulin and/or leptin receptor driven signaling in neurodegenerative processes.

\section{LEPTIN AND EXPRESSION OF LEPTIN RECEP- TORS IN THE BRAIN}

In 1995, the leptin receptor (Ob-R) was cloned from mouse choroid plexus using expression cloning techniques [14]. Genetic mapping studies revealed that $\mathrm{Ob}-\mathrm{R}$ is encoded by a gene located within the $5.1 \mathrm{cM}$ interval of mouse chromosome 4 that comprises the $d b$ (diabetes) locus. The leptin receptor displays greatest homology to the class I cytokine receptor superfamily; a group of receptors that includes the interleukin 6 and granulocyte-colony stimulating factor receptors [15]. These receptors have characteristic extracellular regions that include WSXWS, four cysteine residues as well as numerous fibronectin type III domains [16]. Indeed, the extracellular region of $\mathrm{Ob}-\mathrm{R}$ has four fibronectin domains and two cytokine receptor domains [17].

Six leptin receptor isoforms, generated by alternate splicing of the $d b$ gene, have been identified in rodents [18]. These isoforms, termed Ob-Ra to Ob-Rf have identical Nterminal extracellular domains, but have distinct intracellular $\mathrm{C}$-terminal regions. All the isoforms, except Ob-Re, are membrane spanning receptors that contain a 34 amino acid transmembrane domain. As Ob-Re is not associated with the plasma membrane and it is a major site for leptin binding in the plasma, it is thought to act as a soluble receptor that enables transport of leptin within the plasma. The remaining isoforms fall into two distinct categories based on the length of the C-terminal domain: short forms of the receptor $(\mathrm{Ob}-$ $\mathrm{Ra}, \mathrm{c}, \mathrm{d}, \mathrm{f})$ with short intracellular domains, and a long form $(\mathrm{Ob}-\mathrm{Rb})$ of the receptor with a larger intracellular domain (302 residues) that contains various motifs that enable the initiation of various downstream signaling cascades.

In both rodents and humans, the levels of leptin receptor mRNA and protein are particularly high in specific regions of the hypothalamus that are involved in regulating food intake and body weight, such as the ventromedial hypo- 
thalamus, arcuate nucleus and dorsomedial hypothalamus [19-22]. However, several studies have demonstrated that Ob-R expression is not confined to the hypothalamus. Indeed, high levels of leptin receptor mRNA and immunoreactivity have been detected in numerous extra-hypothalamic brain regions including amygdala, cerebellum, brainstem, substantia nigra and hippocampus [21-24]. In the human cerebellum, Ob-R mRNA is expressed at significantly higher levels than found in the hypothalamus [25]. In rodents Ob-R expression is also evident in cerebellar neurons [21, 26], with high levels of expression found during both embryonic and postnatal stages of development [21, 27, 28]. High levels of leptin receptor mRNA and immunoreactivity have been observed in hippocampal CA1/CA3 regions and in the dentate gyrus $[22,23,29]$. In primary hippocampal cultures, leptin receptors are expressed on the principle pyramidal neurons and on glial cells [30]. Furthermore, in a manner comparable to cerebellar granule cells, leptin receptor immunostaining is associated with axonal and somato-dendritic regions as well as points of synaptic contact [30].

\section{TRANSPORT OF LEPTIN INTO THE BRAIN}

The main route of leptin transport into the brain is via a saturable transport system [31]. Indeed, the short leptin receptor isoforms are highly expressed on brain microvessels and are able to bind and subsequently internalize leptin [32]. Recent studies have demonstrated that the leptin transport system can be regulated by a number of factors including triglycerides and epinephrine [7, 33]. Moreover impairments in the transport mechanism have been linked to the development of obesity, suggesting that resistance to leptin may occur at the level of the blood brain barrier [34]. Leptin is also thought to reach the brain via the cerebrospinal fluid (CSF) as high levels of ObRa have been detected on the main site for CSF production, the choroid plexus [35]. A number of studies have also shown that leptin mRNA and immunoreactivity are expressed widely in the brain [36, 37]. Thus the possibility that leptin is made and released locally in the CNS cannot be excluded.

\section{INSULIN RECEPTOR EXPRESSION IN THE BRAIN}

For many years it was generally thought that the peripherally derived hormone insulin was unable to enter the CNS and thus influence neuronal function. However, the first evidence that insulin may have central actions came from the identification of insulin receptor binding sites in the CNS [38-40]. Subsequent studies demonstrated the wide-spread expression of insulin receptors on neurons and glial cells in rat brain, with particularly high levels detected in the olfactory bulb, hippocampus, hypothalamus and cortex [39]. At the sub-cellular level, a combination of biochemical and immunocytochemical approaches have shown that insulin receptors are expressed at hippocampal synapses [41].

\section{ORIGIN OF BRAIN INSULIN}

Until around 10 years ago it was generally assumed that the CNS was insensitive to the circulating peripheral levels of insulin. However there is now considerable evidence for the existence of a saturable insulin transporter that enables peripherally-derived insulin to enter the brain via the blood brain barrier [42; for review]. The rate of insulin entry into the brain is influenced by many factors including fasting, refeeding as well as a number of pathological conditions [43]. Studies in neuronal tissue and cultures have detected the expression of insulin mRNA in a number of brain regions $[44,45]$. Moreover, insulin is reportedly secreted from neurons in a calcium-dependent manner when depolarized [46]. Thus together these finding indicate that insulin can enter the brain via a regulated transport mechanism but also that this hormone has the potential to be made and released from neurons.

\section{LEPTIN RECEPTOR SIGNAL TRANSDUCTION}

The leptin receptor displays greatest homology with class I cytokine receptors and the signaling cascades activated downstream of leptin receptors are analogous to those activated by other members of this receptor superfamily. Thus, following leptin binding, janus tyrosine kinases (JAKs), in particular JAK2 associates with specific cytoplasmic domains of the leptin receptor, resulting in trans-phosphorylation of JAK2 and subsequent phosphorylation of tyrosine residues on the leptin receptor. This chain of events in turn leads to the recruitment and activation of various downstream signaling molecules, including the STAT (signal transducers and activators of transcription) family of transcription factors, insulin receptor substrate (IRS) proteins, phosphoinositide 3-kinase (PI 3-kinase) and adaptor protein associated with the Ras-Raf-MAPK (mitogen-activated protein kinase) signaling cascade.

\section{INSULIN RECEPTOR SIGNALING}

Insulin receptors are members of the tyrosine kinase receptor superfamily. The insulin receptor is a tetramer comprising of two extracellular $\alpha$ subunits and two $\beta$ subunits that are located intracellularly. Insulin binding results in rapid autophosphorylation of the insulin receptor $\beta$ subunits which in turn promotes recruitment of various SH2 and PTB domain-containing scaffold proteins, in particular the IRS proteins. Once recruited to the $\beta$ subunit these proteins are phosphorylated on tyrosine residues which enables recruitment of various effector molecules. The main signaling pathways activated downstream of the phosphorylated IRS proteins are the Ras-Raf-MAPK and PI 3-kinase cascades.

\section{CONVERGENCE OF LEPTIN AND INSULIN DRIVEN SIGNALING}

Several lines of evidence indicate that leptin and insulin signaling networks converge at a number of levels. In hepatocytes leptin reduces insulin-induced gluconeogenesis and tyrosine phosphorylation of IRS-1 by insulin [47]. Moreover the effects of insulin on hepatic glucose metabolism are enhanced by leptin [48]. In an insulin-secreting cell line $\mathrm{K}_{\mathrm{ATP}}$ channel activation by leptin is occluded by insulin [49]. In hypothalamic neurons the ability of leptin to activate $K_{\text {ATP }}$ channels is mimicked by insulin [50] and the ability of both these hormones to stimulate $\mathrm{K}_{\mathrm{ATP}}$ channel activation involves PI 3-kinase-driven actin filament disruption [51,52]. Actin filament disruption also plays a pivotal role in the activation of hippocampal BK channels by leptin and insulin however divergent signaling pathways couple these hormone receptors to changes in actin dynamics and subsequent channel activation [53-55]. 


\section{LEPTIN AND SYNAPTIC PLASTICITY}

There have been numerous reports implicating leptin in the regulation of hippocampal synaptic transmission and synaptic plasticity. In the mammalian CNS, excitatory synaptic transmission is predominantly mediated by the AMPA subtype of glutamate receptors. In contrast NMDA receptors contribute little to basal synaptic transmission but are required for the induction of certain forms of synaptic plasticity including hippocampal long-term potentiation (LTP) and long-term depression (LTD). Initially cellular studies by Shanley et al. (2001) [56] demonstrated that leptin selectively enhanced NMDA receptor-mediated synaptic transmission at hippocampal CA1 synapses. Moreover, exposure of acute hippocampal slices to leptin promoted the conversion of short term potentiation (STP) into LTP, indicating that this hormone has the ability to facilitate NMDA receptor-dependent LTP. Additional electrophysiological studies on Xenopus oocytes expressing recombinant NMDA channels showed that leptin receptor activation was required for facilitation of NMDA-evoked currents [56]. Moreover, using this approach Harvey et al. (2005) identified that changes in the trafficking of NMDA receptors is likely to underlie facilitation of NMDA receptor-mediated currents by leptin [57]. Recent studies also support a role for leptin in hippocampal synaptic plasticity as direct administration of leptin into the dentate gyrus enhances the level of hippocampal LTP [58]. Leptin-insensitive rodents with dysfunctional leptin receptors $(d b / d b$ mice or Zucker $f a / f a$ rats) exhibit impaired hippocampal LTP and LTD [59] and deficits in hippocampal-dependent memory tasks [59,60]. More recent cellular studies have reported that leptin promotes rapid remodeling of hippocampal dendrites and increases the density of hippocampal synapses [61]; structural changes that are likely to play an important role in synaptic plasticity as numerous lines of evidence indicate that morphological changes in dendrites/synapses are pivotal for hippocampal LTP.

A number of studies have examined the cell signaling cascades coupling leptin receptor activation to its effects on hippocampal synaptic plasticity. Inhibitors of PI 3-kinase and MAPK (ERK) prevent facilitation of NMDA receptor mediated responses by leptin thereby indicating that this process is mediated by PI 3-kinase and MAPK-dependent signaling [56]. In contrast, the rapid remodeling of dendrites by leptin requires the activation of NR2A-containing NMDA receptors, which is mediated by a MAPK, but not PI 3kinase driven process [61]. It is known that NMDA receptors comprise an NR1 subunit and at least one copy of NR2A, $2 \mathrm{~B}, 2 \mathrm{C}$ or D, with or without an NR3 subunit. Moreover several lines of evidence indicate not only that NR2 subunits regulate the receptor biophysical and pharmacological properties, but also that these subunits are differentially expressed and have distinct functions in the CNS. In view of this, it is feasible that leptin displays subunit-specificity in its ability to modulate NMDA receptor-dependent synaptic function and plasticity. In support of this possibility, leptin enhances NR2B-, but not NR2A-mediated responses in cerebellar granule cells [28]. It is also possible that distinct signaling cacades link leptin receptors to different combinations of NMDA receptor subunits. Indeed, leptin facilitation of NR2B-mediated responses in cerebellar granule cells in- volves a MAPK-, but not a PI 3-kinase-, dependent process [28].

In addition to influencing hippocampal LTP, a recent study demonstrated that leptin evokes a novel form of NMDA receptor-dependent LTD [62]. As leptin-induced LTD was observed following removal of extracellular $\mathrm{Mg}^{2+}$, this suggests that this form of synaptic plasticity occurs under conditions of enhanced excitability. This form of LTD displays parallels to that evoked following low frequency stimulation (LFS) as it is NMDA receptor-dependent, has a postsynaptic locus of expression and is independent of mGluRs. However, the signaling pathways underlying leptin-induced LTD are distinct from LFS-induced LTD as it is negatively regulated by PI 3-kinase and serine/threonine phosphatases $1 / 2 \mathrm{~A}$ [62]. In conclusion, leptin has the ability to influence different forms of hippocampal synaptic plasticity which in turn is likely to have important implications for the role of this hormone in neuronal development as well as learning and memory.

It is known that the circulating plasma levels of leptin are usually in the low nanomolar range $(0.1-10 \mathrm{nM})$ and are related to body adiposity. However during the first 2-3 weeks of postnatal development, before leptin plays a role in the regulation of food intake and body weight, the circulating levels of leptin are around 5-10 fold higher [63]. In most of the above studies examining the effects of leptin on hippocampal synaptic function, the concentrations of leptin utilized are well within the range likely to reach the hippocampus during early neuronal development and as such are likely to closely correlate with the physiological effects of this hormone at this stage of development. However, it is also likely that leptin plays a role in hippocampal synaptic function at later stages of development and in the ageing process. Indeed, the concentrations of leptin reaching this brain region may be derived not only from peripheral sources, but also from locally released leptin, as leptin mRNA and protein have been detected in the hippocampal formation.

\section{INSULIN AND SYNAPTIC FUNCTION/PLASTICITY}

In a manner similar to leptin, insulin has the ability to influence excitatory synaptic transmission and synaptic plasticity in the CNS. In hippocampal slices, brief application of low micromolar concentrations of insulin (concentrations that are only likely to occur during early stages of neuronal development; [44]), evokes a long-lasting depression (LTD) of excitatory synaptic transmission [64-66]. Like LTD induced by LFS and leptin, insulin-induced LTD is NMDA receptor-dependent, expressed postsynaptically and is independent of mGluR activation. Several reports have implicated a number of signaling pathways in insulin-induced LTD including PI 3-kinase and PKC [65, 66]. Moreover, recent studies have shown that an increased internalization of GluR2 AMPA receptor subunits $[64,65]$, as well tyrosine phosphorylation of GluR2 are required for the synaptic depression induced by insulin [67].

Conversely, the cell surface expression of GluR1, but not GluR2, is elevated following exposure of hippocampal neurons to insulin [64, 68]. As an increase in the cell surface expression of GluR1 underlies the increase in synaptic strength associated with hippocampal LTP [69], this suggests that insulin also has the capacity to enhance the strength of 
excitatory synaptic transmission via this process. Indeed, insulin facilitates the induction of LTP at lower stimulation frequencies than under control conditions [66]. Moreover insulin enhances NMDA receptor mediated currents in hippocampal neurons [70] and it promotes an increase in the cell surface density of NMDA receptors [11]; effects that are likely to promote the induction of hippocampal LTP. In contrast, rodents with streptozotocin-induced diabetes (hypoinsulinamemic conditions) display deficits in NMDA receptordependent signaling which may in turn reduce the likelihood of LTP induction [71]. Protein kinase C (PKC) is one potential mediator coupling insulin to NMDA receptors as selective PKC inhibitors prevent the potentiation of NMDA receptor activity by insulin [72]. Indeed, PKC plays a key role in modulating NMDA receptor trafficking and gating [73]. Recent studies have also demonstrated that as the scaffold protein, PSD-95 regulates the surface expression and channel gating properties of NMDA receptors [74]. As insulin increases the expression of PSD-95 in the hippocampal CA1 region, via a PI 3-kinase-dependent mechanism [75], another possible candidate mediating insulin coupling to NMDA receptors is PI 3-kinase. In support of this possibility, PI 3kinase forms a complex with AMPA receptors and PI 3kinase activity is required for AMPA receptor insertion during LTP [76].

Changes in the insulin receptor system have also been detected in the hippocampus of rodents following training in spatial memory tasks. Indeed, training was associated with an upregulation of insulin receptor mRNA, increased tyrosine phosphorylation of the insulin receptor as well as activation of the MAPK signaling cascade [77]. This not only provides further indirect evidence implicating the insulin system in cognitive functions such as learning and memory, but also suggests possible involvement of insulin-driven MAPK signaling in this process.

\section{METABOLIC IMBALANCE AND NEURODEGEN- ERATIVE DISEASE}

A growing body of evidence supports the notion that metabolic imbalance is associated with the development of certain neurodegenerative disorders. Moreover, CNS-driven diseases such as Alzheimer's disease have recently been linked to dysregulation and/or CNS deficiencies in the leptin and insulin receptor systems [78,79]. Indeed, in Alzheimer's disease the circulating leptin levels are attenuated [79] and the CNS levels of insulin are reduced [78]. Furthermore, alterations in the levels of key components of both leptin and insulin signaling cascades have been detected in Alzheimer's disease brains [80], suggesting that impairments in leptin/insulin signaling play a role in the development of this neurodegenerative disease. In mouse models of Alzheimer's disease, administration of leptin significantly decreases the levels of amyloid $\beta$ [81] and it improves performance in hippocampal-dependent memory tasks [82]. It is well documented that one hallmark of Alzheimer's disease is neurofibrillary tangles consisting of aggregates of hyperphosphorylated Tau. Recent studies have shown not only that insulin significantly reduces Tau phosphorylation via inhibition of GSK3 $\beta$ [83], but also that transgenic mice with ablation of neuronal insulin receptors display markedly increased levels of phosphorylated Tau [84]. However, these mice do not display deficits in glucose metabolism or spatial learning and memory, suggesting that lack of neuronal insulin receptors alone is insufficient to result in full-blown Alzheimer's disease pathology. This raises the interesting possibility that alterations in both insulin and leptin systems play a role in the development of this disease. However, little is known about how these two hormonal systems interact at the neuronal level and in turn how such interactions are deregulated or altered in neurodegenerative diseases.

\section{CONCLUSIONS}

Evidence is growing that the endocrine hormones, leptin and insulin, have multiple roles in the brain. Indeed, both hormones not only markedly influence hippocampal excitatory synaptic transmission but are also implicated in the cellular events underlying learning and memory. The discovery of alterations in the levels of these hormones in Alzheimer's disease, together with deficits in leptin/insulin signaling molecules has led to the suggestion that impairments and/or dysregulation of the leptin and insulin systems contribute to the development of neurodegenerative disorders associated with cognitive deficits. Thus, a greater understanding of the interplay between these hormones in neurons is required as it is likely that disturbances in both neuronal leptin and insulin systems play a role in the development of these diseases.

\section{ACKNOWLEDGEMENTS}

$\mathrm{JH}$ is a Wellcome funded Lecturer and is supported by grants from The Wellcome Trust, Medical Research Scotland, Tenovus Scotland and The Royal Society.

\section{REFERENCES}

[1] Maffei M, Halaas J, Ravussin E, et al. Leptin levels in human and rodent: measurement of plasma leptin and ob RNA in obese and weight-reduced subjects. Nat Med 1995; 1: 1155-61.

[2] Considine RV, Sinha MK, Heiman ML, et al. Serum immunoreactive-leptin concentrations in normal-weight and obese humans. N Engl J Med 1996; 334: 292-5.

[3] Spiegelman BM, Flier JS. Obesity and the regulation of energy balance. Cell 2001; 104: 531-43.

[4] Karsenty G. Convergence between bone and energy homeostases: leptin regulation of bone mass. Cell Metab 2006; 4: 341-8.

[5] Cervero A, Dominguez F, Horcajadas JA, Quinonero A, Pellicer A, Simon C. The role of the leptin in reproduction. Curr Opin Obstet Gynecol 2006; 18: 297-303.

[6] Malendowicz LK, Rucinski M, Belloni AS, Ziolkowska A, Nussdorfer GG. Leptin and the regulation of the hypothalamicpituitary-adrenal axis. Int Rev Cytol 2007; 263: 63-102.

[7] Banks WA. The source of cerebral insulin. Eur J Pharmacol 2004; 490: 5-12.

[8] Niswender KD, Schwartz MW. Insulin and leptin revisited: adiposity signals with overlapping physiological and intracellular signaling capabilities. Front Neuroendocrinol 2003; 24: 1-10.

[9] Wang YT, Linden DJ. Expression of cerebellar long-term depression requires postsynaptic clathrin-mediated endocytosis. Neuron 2000; 25: 635-47.

[10] Wan Q, Xiong ZG, Man HY, et al. Recruitment of functional GABA(A) receptors to postsynaptic domains by insulin. Nature 1997; 388: 686-90.

[11] Skeberdis VA, Lan J, Zheng X, Zukin RS, Bennett MV. Insulin promotes rapid delivery of N-methyl-D- aspartate receptors to the cell surface by exocytosis. Proc Natl Acad Sci USA 2001; 98: 3561-6.

[12] van der Heide LP, Ramakers GM, Smidt MP. Insulin signaling in the central nervous system: learning to survive. Prog Neurobiol 2006; 79: 205-21.

[13] Craft S, Peskind E, Schwartz MW, Schellenberg GD, Raskind M, Porte D Jr. Cerebrospinal fluid and plasma insulin levels in Alzheimer's disease: relationship to severity of dementia and apolipoprotein E genotype. Neurology 1998; 50: 164-8. 
[14] Tartaglia LA, Dembski M, Weng X, et al. Identification and expression cloning of a leptin receptor, OB-R. Cell 1995; 83: 126371.

[15] Tartaglia LA. The leptin receptor. J Biol Chem 1997; 272: 6093-6.

[16] Heim MH. The Jak-STAT pathway: specific signal transduction from the cell membrane to the nucleus. Eur J Clin Invest 1996; 26: $1-12$.

[17] Heshka JT, Jones PJ. A role for dietary fat in leptin receptor, OB$\mathrm{Rb}$, function. Life Sci 2001; 69: 987-1003.

[18] Lee GH, Proenca R, Montez JM, et al. Abnormal splicing of the leptin receptor in diabetic mice. Nature 1996; 379: 632-5.

[19] Schwartz MW, Seeley RJ, Campfield LA, Burn P, Baskin DG. Identification of targets of leptin action in rat hypothalamus. J Clin Invest 1996; 98: 1101-6.

[20] Savioz A, Charnay Y, Huguenin C, Graviou C, Greggio B, Bouras C. Expression of leptin receptor mRNA (long form splice variant) in the human cerebellum. Neuroreport 1997; 8: 3123-6.

[21] Elmquist JK, Bjorbaek C, Ahima RS, Flier JS, Saper CB. Distributions of leptin receptor mRNA isoforms in the rat brain. J Comp Neurol 1998; 395: 535-47.

[22] Hakansson ML, Brown H, Ghilardi N, Skoda RC, Meister B. Leptin receptor immunoreactivity in chemically defined target neurons of the hypothalamus. J Neurosci 1998; 18: 559-72.

[23] Mercer JG, Hoggard N, Williams LM, Lawrence CB, Hannah LT, Trayhurn P. Localization of leptin receptor mRNA and the long form splice variant $(\mathrm{Ob}-\mathrm{Rb})$ in mouse hypothalamus and adjacent brain regions by in situ hybridization. FEBS Lett 1996; 387: 113-6.

[24] Figlewicz DP, Evans SB, Murphy J, Hoen M, Baskin DG. Expression of receptors for insulin and leptin in the ventral tegmental area/substantia nigra (VTA/SN) of the rat. Brain Res 2003; 964: 107-15.

[25] Burguera B, Couce ME, Long J, et al. The long form of the leptin receptor (OB-Rb) is widely expressed in the human brain. Neuroendocrinology 2000; 71: 187-95.

[26] Udagawa J, Hatta T, Naora H, Otani H. Expression of the long form of leptin receptor (Ob-Rb) mRNA in the brain of mouse embryos and newborn mice. Brain Res 2000; 868: 251-8.

[27] Udagawa J, Hashimoto R, Hioki K, Otani H. The role of leptin in the development of the cortical neuron in mouse embryos. Brain Res 2006; 1120: 74-82.

[28] Irving AJ, Wallace L, Durakoglugil D, Harvey J. Leptin enhances NR2B-mediated N-Methyl-D-Aspartate responses via a mitogenactivated protein kinase-dependent process in cerebellar granule cells. Neuroscience 2006; 138: 1137-48.

[29] Huang XF, Koutcherov I, Lin S, Wang HQ, Storlien L. Localization of leptin receptor mRNA expression in mouse brain. Neuroreport 1996; 7: 2635-8.

[30] Shanley LJ, O'Malley D, Irving AJ, Ashford ML, Harvey J. Leptin inhibits epileptiform-like activity in rat hippocampal neurones via PI 3-kinase-driven activation of BK channels. J Physiol 2002; 545: 933-44.

[31] Banks WA, Kastin AJ, Huang W, Jaspan JB, Maness LM. Leptin enters the brain by a saturable system independent of insulin. Peptides 1996; 17: 305-11.

[32] Bjørbaek C, Elmquist JK, Michl P, Ahima RS, van Bueren A, McCall AL, Flier JS. Expression of leptin receptor isoforms in rat brain microvessels. Endocrinology 1998; 139: 3485-91.

[33] Banks WA. Enhanced leptin transport across the blood-brain barrier by alpha 1-adrenergic agents. Brain Res 2001; 899: 209-17.

[34] Banks WA, Farrell CL. Impaired transport of leptin across the blood-brain barrier in obesity is acquired and reversible. Am J Physiol Endocrinol Metab 2003; 285: E10-5.

[35] Schwartz MW, Peskind E, Raskind M, Boyko EJ, Porte D Jr. Cerebrospinal fluid leptin levels: Relationship to plasma levels and to adiposity in humans. Nat Med 1996; 2: 589-93.

[36] Morash B, Li A, Murphy PR, Wilkinson M, Ur E. Leptin gene expression in the brain and pituitary gland. Endocrinology 1999; 140: 5995-8.

[37] Ur E, Wilkinson DA, Morash BA, Wilkinson M. Leptin immunoreactivity is localized to neurons in rat brain. Neuroendocrinology 2002; 75: 264-72.

[38] Havrankova J, Brownstein M, Roth J. Insulin and insulin receptors in rodent brain. Diabetologia 1981; 20 (Suppl): 268-73.

[39] Havrankova J, Schmechel D, Roth J, Brownstein M. Identification of insulin in rat brain. Proc Natl Acad Sci USA 1978; 75: 5737-41.
[40] Plum L, Schubert M, Brüning JC. The role of insulin receptor signaling in the brain. Trends Endocrinol Metab 2005; 16: 59-65.

[41] Abbott MA, Wells DG, Fallon JR. The insulin receptor tyrosine kinase substrate p58/53 and the insulin receptor are components of CNS synapses. J Neurosci 1999; 19: 7300-8.

[42] Banks WA. Blood-brain barrier and energy balance. Obesity (Silver Spring). 2006; 14(Suppl 5): 234S-237S

[43] Woods SC, Seeley RJ, Baskin DG, Schwartz MW. Insulin and the blood-brain barrier. Curr Pharm Des 2003; 9: 795-800.

[44] Schechter R, Whitmire J, Wheet GS, et al. Immunohistochemical and in situ hybridization study of an insulin-like substance in fetal neuron cell cultures. Brain Res 1994; 636: 9-27.

[45] Devaskar SU, Giddings SJ, Rajakumar PA, Carnaghi LR, Menon $\mathrm{RK}$, Zahm DS. Insulin gene expression and insulin synthesis in mammalian neuronal cells. J Biol Chem 1994; 269: 8445-54.

[46] Clarke DW, Mudd L, Boyd FT Jr, Fields M, Raizada MK. Insulin is released from rat brain neuronal cells in culture. $\mathrm{J}$ Neurochem 1986; 47: 831-6.

[47] Cohen B, Novick D, Rubinstein M. Modulation of insulin activities by leptin. Science 1996; 274: 1185-8.

[48] Aiston S, Agius L. Leptin enhances glycogen storage in hepatocytes by inhibition of phosphorylase and exerts an additive effect with insulin. Diabetes 1999; 48: 15-20.

[49] Harvey J, Ashford ML. Insulin occludes leptin activation of ATPsensitive $\mathrm{K}+$ channels in rat CRI-G1 insulin secreting cells. Physiol 1998; 511, 695-706.

[50] Spanswick D, Smith MA, Mirshamsi S, Routh VH, Ashford ML Insulin activates ATP-sensitive $\mathrm{K}+$ channels in hypothalamic neurons of lean, but not obese rats. Nat Neurosci 2000; 3: 757-8.

[51] Harvey J, Hardy SC, Irving AJ, Ashford ML. Leptin activation of ATP-sensitive K+ (KATP) channels in rat CRI-G1 insulinoma cells involves disruption of the actin cytoskeleton. J Physiol 2000; 527: 95-107.

[52] Mirshamsi S, Laidlaw HA, Ning K, et al. Leptin and insulin stimulation of signalling pathways in arcuate nucleus neurones: PI3K dependent actin reorganization and KATP channel activation. BMC Neurosci 2004; 5: 54.

[53] O'Malley D, Harvey J. Insulin activates native and recombinant large conductance $\mathrm{Ca}(2+)$-activated potassium channels via a mitogen-activated protein kinase-dependent process. Mol Pharmacol 2004; 65: 1352-63.

[54] O'Malley D, Irving AJ, Harvey J. Leptin-induced dynamic alterations in the actin cytoskeleton mediate the activation and synaptic clustering of BK channels. FASEB J 2005; 19: 1917-9.

[55] O'Malley D, Harvey J. MAPK-dependent actin cytoskeletal reorganization underlies BK channel activation by insulin. Eur J Neurosci 2007; 25: 673-82.

[56] Shanley LJ, Irving AJ, Harvey J. Leptin enhances NMDA receptor function and modulates hippocampal synaptic plasticity. J Neurosci 2001; 21: RC186.

[57] Harvey J, Shanley LJ, O'Malley D, Irving AJ. Leptin: a potential cognitive enhancer? Biochem Soc Trans 2005; 33: 1029-32.

[58] Wayner MJ, Armstrong DL, Phelix CF, Oomura Y. Orexin-A (Hypocretin-1) and leptin enhance LTP in the dentate gyrus of rats in vivo. Peptides 2004; 25: 991-6.

[59] Li XL, Aou S, Oomura Y, Hori N, Fukunaga K, Hori T. Impairment of long-term potentiation and spatial memory in leptin receptor-deficient rodents. Neuroscience 2002; 113: 607-15.

[60] Winocur G, Greenwood CE, Piroli GG, et al. Memory impairment in obese Zucker rats: an investigation of cognitive function in an animal model of insulin resistance and obesity. Behav Neurosci 2005; 119: 1389-95

[61] O'Malley D, Macdonald N, Mizielinska S, Connolly CN, Irving AJ, Harvey J. Leptin promotes rapid dynamic changes in hippocampal dendritic morphology. Mol Cell Neurosci 2007; 35: 559-72

[62] Durakoglugil M, Irving AJ, Harvey J. Leptin induces a novel form of NMDA receptor-dependent long-term depression. J Neurochem 2005; 95: 396-405.

[63] Ahima RS, Prabakaran D, Flier JS. Postnatal leptin surge and regulation of circadian rhythm of leptin by feeding. Implications for energy homeostasis and neuroendocrine function. J Clin Invest 1998; 101: 1020-7.

[64] Man HY, Lin JW, Ju WH, et al. Regulation of AMPA receptormediated synaptic transmission by clathrin-dependent receptor internalization. Neuron 2000; 25: 649-62. 
[65] Huang CC, Lee CC, Hsu KS. An investigation into signal transduction mechanisms involved in insulin-induced long-term depression in the CA1 region of the hippocampus. J Neurochem 2004; 89: 217-31.

[66] van der Heide LP, Kamal A, Artola A, Gispen WH, Ramakers GM. Insulin modulates hippocampal activity-dependent synaptic plasticity in a N-methyl-d-aspartate receptor and phosphatidyl-inositol-3kinase-dependent manner. J Neurochem 2005; 94: 1158-66.

[67] Ahmadian G, Ju W, Liu L, et al. Tyrosine phosphorylation of GluR2 is required for insulin-stimulated AMPA receptor endocytosis and LTD. EMBO J 2004; 23: 1040-50.

[68] Passafaro M, Piëch V, Sheng M. Subunit-specific temporal and spatial patterns of AMPA receptor exocytosis in hippocampal neurons. Nat Neurosci 2001; 4: 917-26.

[69] Collingridge GL, Isaac JT, Wang YT. Receptor trafficking and synaptic plasticity. Nat Rev Neurosci 2004; 5: 952-62.

[70] Liu L, Brown JC 3rd, Webster WW, Morrisett RA, Monaghan DT. Insulin potentiates $\mathrm{N}$-methyl-D-aspartate receptor activity in Xenopus oocytes and rat hippocampus. Neurosci Lett 1995; 192: 5-8.

[71] Di Luca M, Ruts L, Gardoni F, Cattabeni F, Biessels GJ, Gispen WH. NMDA receptor subunits are modified transcriptionally and post-translationally in the brain of streptozotocin-diabetic rats. Diabetologia 1999; 42: 693-701.

[72] Liao GY, Leonard JP. Insulin modulation of cloned mouse NMDA receptor currents in Xenopus oocytes. J Neurochem 1999; 73: $1510-9$.

[73] Lan JY, Skeberdis VA, Jover T, et al. Protein kinase C modulates NMDA receptor trafficking and gating. Nat Neurosci 2001; 4: 38290.

[74] Lin Y, Skeberdis VA, Francesconi A, Bennett MV, Zukin RS. Postsynaptic density protein-95 regulates NMDA channel gating and surface expression. J Neurosci 2004; 24(45): 10138-48.
[75] Lee CC, Huang CC, Wu MY, Hsu KS. Insulin stimulates postsynaptic density-95 protein translation via the phosphoinositide 3kinase-Akt-mammalian target of rapamycin signaling pathway. J Biol Chem 2005; 280: 18543-50.

[76] Man HY, Wang Q, Lu WY, et al. Activation of PI3-kinase is required for AMPA receptor insertion during LTP of mEPSCs in cultured hippocampal neurons. Neuron 2003; 38: 611-24.

[77] Zhao W, Chen $\mathrm{H}, \mathrm{Xu} \mathrm{H}$, et al. Brain insulin receptors and spatial memory. Correlated changes in gene expression, tyrosine phosphorylation, and signaling molecules in the hippocampus of water maze trained rats. J Biol Chem 1999; 274: 34893-902.

[78] Craft S. Insulin resistance and Alzheimer's disease pathogenesis: potential mechanisms and implications for treatment. Curr $\mathrm{Alz}$ heimer Res 2007; 4: 147-52.

[79] Power DA, Noel J, Collins R, O'Neill D. Circulating leptin levels and weight loss in Alzheimer's disease patients. Dement Geriatr Cogn Disord 2001; 12: 167-70.

[80] Steen E, Terry BM, Rivera EJ, et al. Impaired insulin and insulinlike growth factor expression and signaling mechanisms in Alzheimer's disease--is this type 3 diabetes? J Alzheimers Dis 2005; 7 : 63-80.

[81] Fewlass DC, Noboa K, Pi-Sunyer FX, Johnston JM, Yan SD, Tezapsidis N. Obesity-related leptin regulates Alzheimer's Abeta. FASEB J 2004; 18: 1870-8.

[82] Farr SA, Banks WA, Morley JE. Effects of leptin on memory processing. Peptides 2006; 27: 1420-5.

[83] Lesort M, Johnson GV. Insulin-like growth factor-1 and insulin mediate transient site-selective increases in tau phosphorylation in primary cortical neurons. Neuroscience 2000; 99: 305-16.

[84] Schubert M, Gautam D, Surjo D, et al. Role for neuronal insulin resistance in neurodegenerative diseases. Proc Natl Acad Sci USA 2004; 101: 3100-5. 